\title{
3D Cross Sectional View to Investigate the Morphology of Internat Carotid Artery Plaques. Is 3D Ultrasound Superior to 2D Ultrasound?
}

\author{
3D-Schnittbilder zur Darstellung der Plaquemorphologie der Arteria carotis interna
}

\begin{tabular}{|c|c|}
\hline Authors & C. Denzel', K. Balzer², D. MerhoP, W. Lang' \\
\hline Affilliations & $\begin{array}{l}1 \text { Departement of Surgery, University of Erlangen, Vascular Surgery } \\
2 \text { Evangelic Hospital Mülheim, Vascular Surgery Clinic } \\
3 \text { University of Erlangen, Computer Craphics Group }\end{array}$ \\
\hline
\end{tabular}

Correspondence

Dr. Christian Denzel

Departement of Surgery,

University of Erlangen, Vascular

Surgery

Krankenhausstraße 12

91054 Erlangen

Tel.: $++49 / 9131 / 8532968$

Fax: $++49 / 9131 / 8539115$

christian.denzel@chir.imed.uni-

erlangen.de

\section{Zusammenfassung \\ \%}

Ziel: Die Kenntnis der Plaquemorphologie der Arteria carotis interna spielt zunehmend eine wesentliche Rolle zur Evaluation der Patienten vor Interventionen, da in früheren Studien gezeigt werden konnte, dass Plaques mit einem niedrigen Grauwert eine höhere Komplikationsrate mit sich bringen. Eine immer wieder angegebene Limitation der Ultraschalldiagnostik ist eine lediglich zweidimensionale Darstellung in einer Schallebene, welche zur Berechnung des medianen Grauwertes herangezogen wird.

Material und Methoden: An 24 Thrombendarteriektomie-Präparaten von 19 Patienten wurden anhand von 3D-Datensätzen insgesamt 71 Schnitte untersucht. Die Ultraschalldatensätze wurden mit einem 10-MHz-Schallkopf im 3DModus unter Zuhilfenahme einer speziellen Messkammer gewonnen und von zwei Untersuchern ausgewertet. Zusätzlich wurde von den Präparaten im B-Bild-Modus ein LongitudinalSchnitt nach einem standardisierten Protokoll angefertigt.

Ergebnisse: Es zeigte sich eine hochsignifikante Korrelation der medianen Grauwertverteilung $z$ wischen zwei Untersuchern $(p<0,001$, Intraclass Correlation $[\mathrm{ICC}]>0,895$ ) und zwischen Untersuchungen $\mathrm{zu}$ unterschiedlichen Zeitpunkten bei der Auswertung der 2D- und 3DDatensätze $(p<0,001$, ICC $>0,935)$. Im Vergleich der Auswertung der Querschnitte aus dem 3DDatensatz und dem B-Bild der Längsschnitte zeigte sich ebenfalls eine hochsignifikante Assoziation zwischen den zwei Methoden ( $p<0,001$, $\mathrm{R}=0,800$ ). $92,7 \%$ der Messungen lagen innerhalb den "Limits of agreement" als Zeichen einer hohen Übereinstimmung zwischen den Methoden.

Schlussfolgerung: Durch diese standardisierte „In-vitro“-Untersuchung konnte bei der Evaluation der Echogenität keine Überlegenheit der

\section{Abstract}

Purpose: Previous studies have demonstrated that plaques from the internal carotid artery with lower median grayscale values are associated with higher complication rates in the perinterventional course. A repeatedly cited limitation of ultrasound is that the single plane used to calculate the median grayscale value is only two dimensional. The goal of this study was to compare the median grayscale value as determined using two dimensional cuts versus three dimensional data sets.

Materials and Methods: Seventy-one cuts of 24 thromboendarterectomy samples from 19 patients were analyzed using 3D data sets. The ultrasound data sets were obtained using a $10 \mathrm{MHz}$ probe in 3D mode in a special chamber and were evaluated by two investigators. Additionally, a longitudinal view of the samples was made using B mode according to a standardized protocol.

Results: There was a significant correlation between the 2D and 3D data as assessed by two observers $(p<0.001$, intraclass correlation $[I C C]>0.895)$ and at different times $(p<0,001$, ICC >0.935). Comparison of the 3D transverse cuts with the longitudinal B mode cuts also showed a highly significant association between the two methods $(p<0.001, R=0.800) .97 .2 \%$ of the measured values were within the limits of agreement, reflecting the concordance of the both methods.

Conclusion: The superiority of three dimensional ultrasound with respect to two dimensional ultrasound was not able to be demonstrated using this standardized in vitro procedure to examine the echolucency in extracranial internal carotid artery plaques. 
dreidimensionalen gegenüber der zweidimensionalen Sonografie von Plaques der extrakraniellen Arteria carotis interna nachgewiesen werden.
International randomized studies have proven the benefits of revascularization of the extracranial internal carotid artery for the prevention of stroke [1-3]. In addition to the assessment of the degree of stenosis, imaging of plaque structure is becoming increasingly important, particularly because it has been shown that fatty plaques are associated with a higher risk of embolization than calcium-rich plaques.

A diagnostic procedure that allows for visualization of plaque morphology has not yet succeeded in clinics [4] because none of the available technology is able to give a completely accurate picture of the entire morphology of plaque. Ultrasound, in combination with the evaluation of median grayscale values as an indicator of the echogenicity of the plaque, is used to examine plaque morphology. Computer tomography (CT) and magnetic resonance imaging (MRI) are also used. Such studies have shown that the stroke and death rate is considerably higher for hypoechoic plaques than it is for hyperechoic plaques [5].

The standardized measurements of echogenicity made using digital data transfer for data collection with two-dimensional ultrasound led to findings that were consistently reproducible among different evaluators $[6,7]$. One issue when using ultrasound to evaluate carotid plaques in this context is that the three-dimensional volume can only be seen on two-dimensional cuts.

The goal of this study was to compare the median grayscale value as determined using two-dimensional cuts versus three-dimensional data sets for in vitro imaging of internal carotid artery plaques. Another point to be investigated was whether findings from the three-dimensional method were consistently reproducible.

\section{Materials and Method \\ \%}

\section{Patients}

Twenty-four consecutive internal carotid artery plaques (19 patients, 12 male, 7 female) with a level of stenonsis in excess of $70 \%$ according to NASCET criteria [1] were included. The plaques were all removed by eversion endarterectomy with careful avoidance of artificial lesions. Only samples that were able to be removed en block were included in the analysis. These samples were preserved for further analysis in a $10 \%$ formalin solution. The clinical health of the patients was recorded but not analyzed since the purpose of the study was limited to investigating ultrasound as a plaque imaging technique.

\section{Standardization of the two-dimensional B mode}

The plaques were scanned to evaluate plaque morphology in a $0.9 \%$ saline solution from a distance of $1.5 \mathrm{~cm}$ using a $10 \mathrm{MHz}$ linear probe (Logitec 500, General Electric Company, Fairfield, Massachusetts, USA). The scanner was set to a medium frame rate, time gain compensation longitudinal to blood vessel, linear post-processing curve, minimal persistence, and $60 \mathrm{~dB} d y-$ namic range from the optimal longitudinal position.

\section{Standardization of the three-dimensional B mode}

To avoid artifacts from reflection, the sample was freely suspended in a chamber designed specifically for this purpose. The sample was able to be moved horizontally along a single plane using a crank ( Fig. 1).

The basic settings on the scanner were identical to those for the two-dimensional scans $(10 \mathrm{MHz}$ probe, $60 \mathrm{~dB}$ dynamic range, $0.9 \%$ saline solution, distance from the sample $1.5 \mathrm{~cm}$ ). For the three-dimensional scans, the plaque was moved at a constant speed under the stationary probe. From this data set, 2 to 4 transverse cuts of the plaque were generated for the analysis, resulting in a total of $713 \mathrm{D}$ cross sectional images (10 Fig. 2).

\section{Image Analysis}

The images that were obtained were saved digitally. The plaque images were analyzed with an image processing program (Adobe Photoshop D 1-6.0, Adobe, USA). Using the method de-
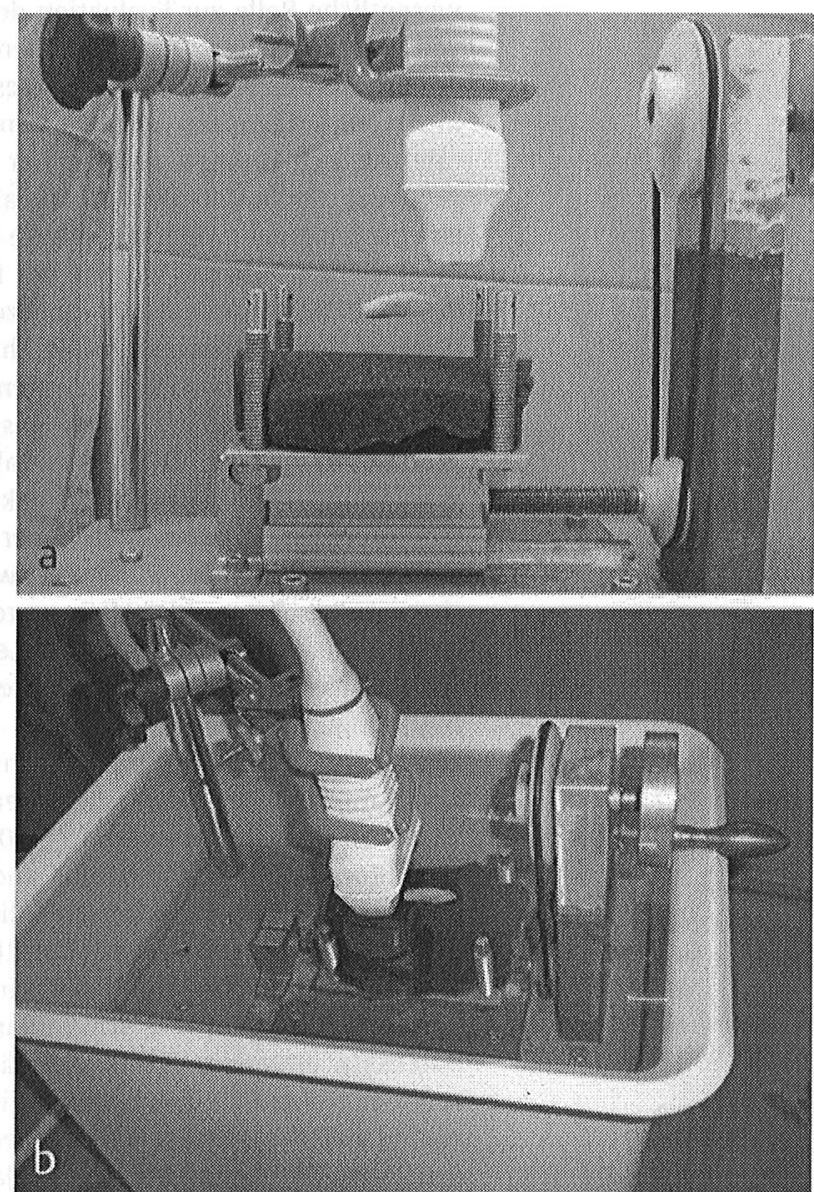

Fig. 1 a Chamber for suspending the plaque to allow for artifact-free scanning. $b$ Diagram of the scanning procedure in the chamber's water bath.

Abb.1 a Messvorrichtung mit der Aufhängung der Plaque, die somit artefaktfrei eingescannt werden kann. b Darstellung des Scan Vorgangs im Wasserbad der Messkammer. 
scribed by Biasi et al., each plaque was outlined via computer mouse. The standardization was made with the help of graduation curves so that a piece of chalk was assigned a gray value of 250 , and the $\mathrm{NaCl}$ solution a gray value of 0 to 5 [8]. In the standardized image the outline of the plaque was marked, and a histogram of the grayscale generated [9]. The median grayscale value describes the proportion of pixels and is a measure of the echogenicity of the entire plaque.

The median grayscale values of the 2D images were directly compared to the 3D data sets ( Fig. 2).

The results were read by two experienced independent investigators, $\mathrm{A}$ and $\mathrm{B}$, at different times, 1 and 2 . There was a period of three months between the first and second reading.

\section{Statistics}

Statistical analysis was performed using the SPSS for Windows software program (SPSS Inc 14.0.1, Chicago, Il, USA) and a Microsoft Excel database. The nonparametric Spearmen's rank order test and intraclass correlation coefficients (ICC) with a twoway random effect for continuous variables were applied to the calculations of the median grayscale value between different investigators and between different times. An error rate of 5\% was defined as the significance limit $(p=0.05)$. For all agreement parameters, $95 \%$ confidence intervals $(\mathrm{CI})$ were calculated.

The graphical method including the limits of agreement $( \pm 2 \mathrm{SD})$ was used to analyze the concordance between the two methods of measurement and the reproducibility of repeated measurements by each of the two methods on the same subject [10].

\section{Results \\ V}

\section{Inter- and intra-observer correlation}

\section{Single longitudinal view}

Grayscale median (GSM) analysis of the longitudinal view at the first time point resulted in a mean value of 56 (sd 13, max 81, $\min 34$ ) for investigator $A$ and 57 (sd 13, $\max 79, \min 30$ ) for investigator $B$. At the second time point, the mean GSM values for longitudinal views were 56 (sd $14, \max 79, \min 40$ ) according to investigator $A$ and 58 (sd 15, $\max 85, \min 29$ ) for investigator $B$. A highly significant correlation with $\mathrm{p}<0.001$ and correlation coefficient $R>0.851$ was seen both between investigators and between the two time points for each investigator. The ICC ranged constantly above 0.930 ( Table 1 ).

\section{Cross sectional view}

The mean median grayscale values for the $3 \mathrm{D}$ cross sectional mode at time 1 were 56 (sd 15, max 96, min 26) and 54 (sd 16 , $\max 92, \min 25$ ) as calculated by investigator $A$ and $B$, respectively. At time 2, investigator $A$ reported a mean of 55 (sd $16, \max 99, \min 27$ ) and investigator $B$ reported a mean of 56 (sd 16, max 93, min 28). Again, there was a highly significant correlation $(p<0.01)$ between time points for each investigator as well as between investigators. The correlation coefficient $R$ was greater than 0.85 for both comparisons ( Fig. 3). The ICC ranged constantly above 0.890 .

\section{Correlation between single longitudinal and 3D cross sectional views}

Due to the strong inter- and intra-observer correlations, only the data from observer $\mathrm{A}$ at time 1 for the $2 \mathrm{D}$ and $3 \mathrm{D}$ data sets was
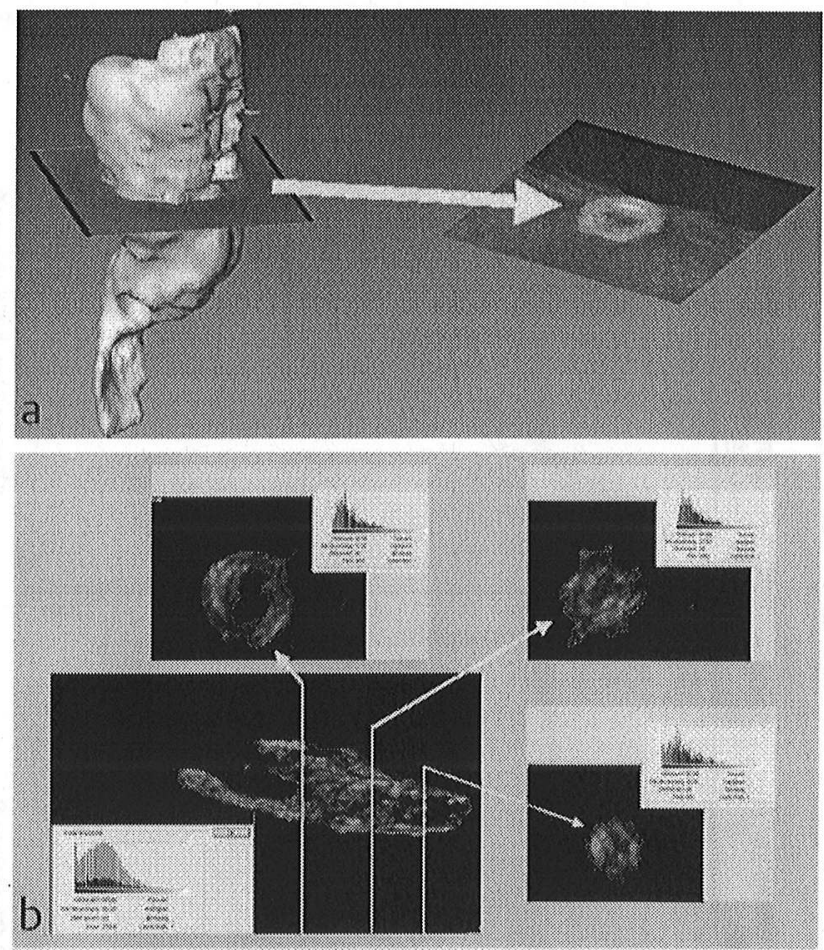

Fig.2 a Schematic diagram of how the cross sectional view is generated from the 3D data set. $b$ Calculation of the median grayscale value in $2 \mathrm{D}$ single longitudinal and 30 cross-sectional mode using image editing software.

Abb. 2a Schematische Darstellung der Generierung der QuerschnittAnsicht aus dem 3D-Datensatz. b Berechnung der medianen Grauwertverteilung im 2D-Längsschnitt und im 3D-Querschnittsverfahren mithilfe eines Bildverarbeitungsprogramms.

Table 1 Demonstration of the intraclass correlation of GSM between different observers and different time points in the longitudinal and the cross sectional view

\begin{tabular}{|c|c|}
\hline & intraclass correlation (95\% CI) \\
\hline \multicolumn{2}{|l|}{ longitudinal view. } \\
\hline observer A: time point 1 and 2 & $0.967(0.948-0.979)$ \\
\hline observer $B$; time point 1 and 2 & $0.935(0.898-0.959)$ \\
\hline observer $A$ and $B$ : time point 1 & $0.969(0.951-0.981)$ \\
\hline observer $A$ and $B$; time point 2 & $0.952(0.924-0.970)$ \\
\hline \multicolumn{2}{|l|}{ cross sectional view } \\
\hline observer A; time point 1 and 2 & $0.936(0.899-0.959)$ \\
\hline observer B; time point 1 and 2 & $0.935(0.897-0.959)$ \\
\hline observer A and B; time point 1 & $0.905(0.852-0.940)$ \\
\hline observer A and B; time point? & $0.895(0.836-0.933)$ \\
\hline
\end{tabular}

analyzed. The analysis showed that there was a highly significant correlation $(p<0.001, R>0.800$ ) between the median grayscale values as determined by the two-dimensional versus threedimensional method.

\section{Agreement between single longitudinal and 3D cross sectional view}

For the same reason mentioned above, only the data from observer $A$ at time 1 were analyzed. The data showed good agreement between the two methods with a limit of agreement between -19.4 and 19.0. The mean difference was -0.2 and the 

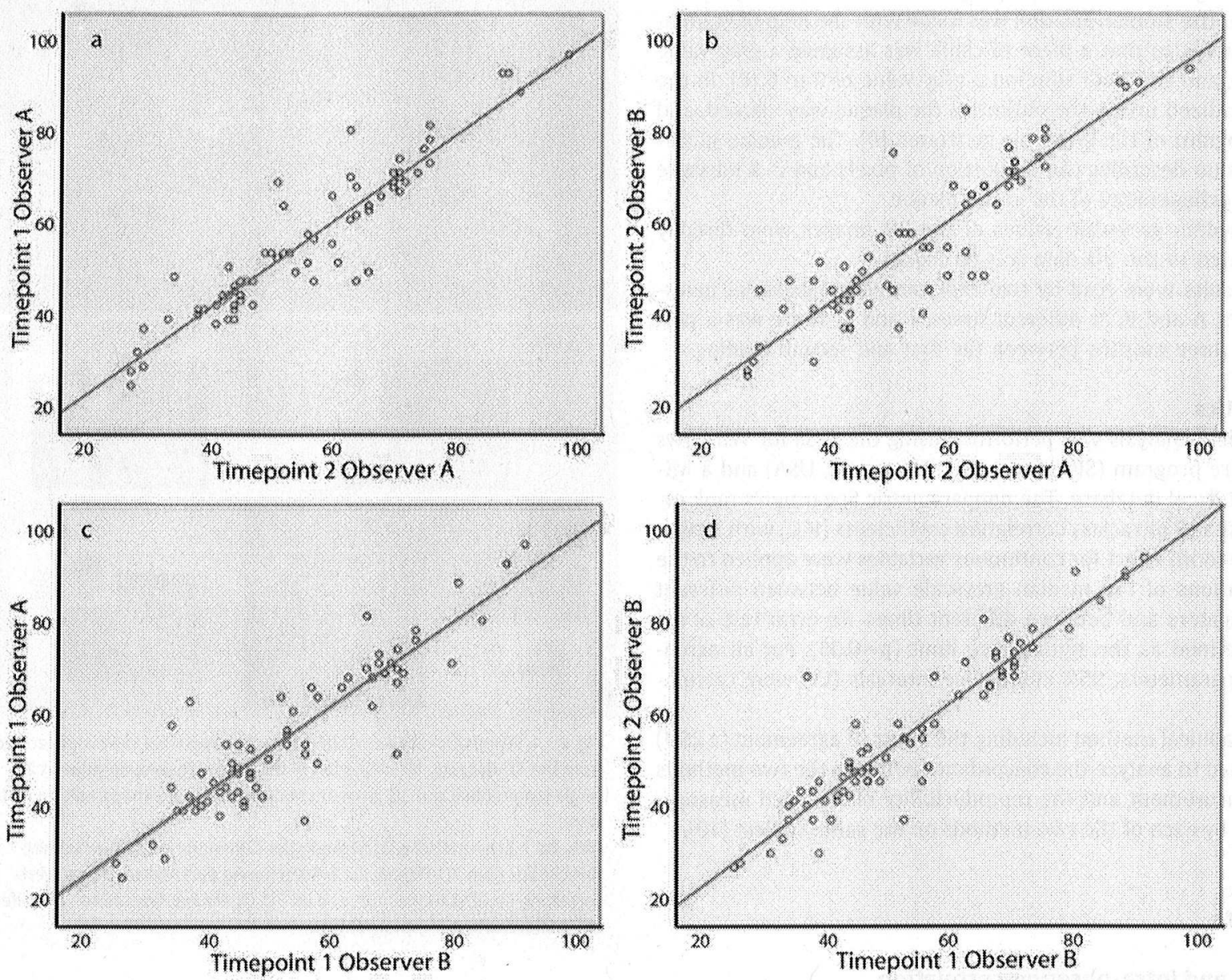

Fig.3 Inter-observer and intra-observer comparison of median grayscale values. Pictured: observer $A$ at different time points $(p<0.01 ; R=0.925$; $I C C=0.936)$, the observers $(A / B)$ at the second time point $(p<0.01$; $R=0.864 ; I C C=0.895) b$, the two observers at time point one $(P<0.01$; $R=0.854 ; I C C=0.905) C$, and observer $B$ at different time points $(p<0.01$; $R=0.905 ;(C C=0.935) d$.

Abb. 3 Dargestellt sind die GSM-Werte von Untersucher A zu verschiedenen Zeitpunkten $(p<0,01 ; R=0,925 ; I C C=0,936)$ a, die Untersucher $(A / B)$ zum Zeitpunkt $2(p<0,01 ; R=0,864 ; I C C=0,895) b$, die zwei Untersucher zu Zeitpunkt eins ( $p<0,01 ; R=0,854 ; I C C=0,905) c$, und Untersucher B zu zwei verschiedenen Zeiten $(p<0,01 ; R=0,905 ; I C C=0,935) d$

95\% confidence interval for the lower limit of agreement ranged from -22.6 to -16.1 and for the upper limit of agreement from 15.7 to 22.8 .

Sixty-nine of 71 values (97.2\%) were inside the limit of agreement and $100 \%$ were identified within the $95 \%$ confidence interval.

Measuring the repeatability of the methods, the limit of agreement ranged between -24.2 and 21.4. Seventy values (98.6\%) were inside these limits. All values were in the $95 \%$ confidence interval for the lower and the upper limits of agreement $(-28.0$ to -20.3 for the lower, 17.5 to 25.3 for the upper $95 \%$ confidence interval) (o Fig. 4).

\section{Discussion}

The importance of diagnosing plaque morphology is not limited to the evaluation of ipsilateral cerebro-vascular risk. Current discussion about carotid angioplasty as an alternative to surgical revascularization emphasizes the importance of risk analysis $[11,12]$. Well investigated is that echolucent plaques are associated with a higher rate of embolization in spontaneous process $[6,13,14]$. However, numerous studies have not been able to demonstrate a correlation between ultrasound findings and plaque histology $[8,15]$. One of the reasons for this is that in vivo evaluations are not three-dimensional $[16,17]$. Another consideration that strengthens the argument for understanding plaque morphology is the fact that large atherosclerotic lesions have histological characteristics that vary over the area of the plaque and therefore do not result in a GSM analysis that accurately represents the entire plaque [18]. Consequently, a three-dimensional method of assessing echogenicity was needed. It was not the aim of this evaluation to determine histology. Because of the comparable results between $2 \mathrm{D}$ and $3 \mathrm{D}$ imaging, we assume no improvement in this aspect. Nevertheless, further evaluation of pathology should follow to investigate this topic specifically. Three-dimensional ultrasound has already been evaluated as a means of measuring plaque volume and the probable volume 


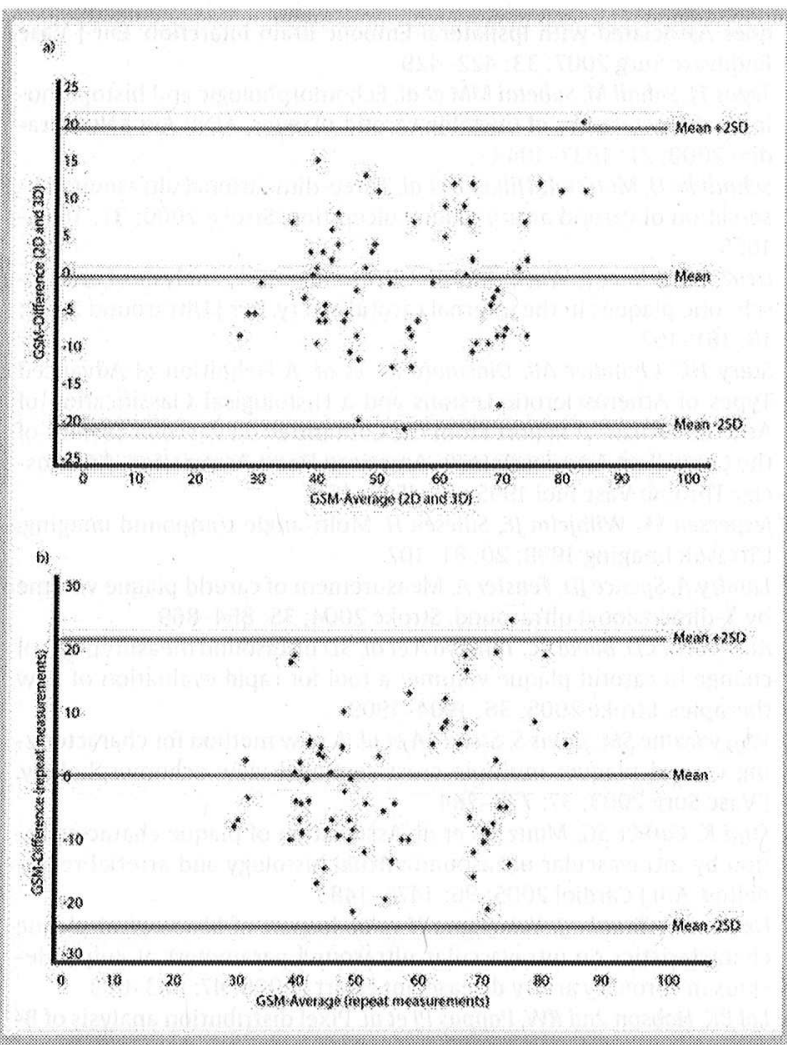

Fig. 4 Difference against mean for CSM data. a Between 2D and 3D eva luation. b Between 2D and 3D evaluation using repeated measurements Abb. 4 Bland-Altmann-Analyse zur Berechnung der Differenz gegenüber dem Mittelwert bei der medianen Grauwertverteilung, a Zwischen 2D. und 3D-Untersuchungen. b Zwischen wiederholten Untersuchungen

progression and was shown to be considerably better than twodimensional studies [19]. It was possible to obtain good observer-independent results with the three-dimensional method [20] which led to the use of the 3D method for evaluating therapeutic effects, e.g. after treatment with statins [21].

However, there are no studies in the current literature that compare echogenicity determined by cross-sectional view versus a volume model.

In this paper, two-dimensional views were compared to views generated by three-dimensional data sets on the basis of median grayscale values.

Since the investigation was intended only to examine the relationship between 2D and 3D modes of ultrasound, no clinical patient data was analyzed. However, previous studies have investigated the connection between multi cross sectional view and the occurrence of clinically relevant events. Those studies showed a good differentiation between symptomatic and asymptomatic plaques [22].

The plaque analyses in the study presented here were conducted in vitro. Standardized conditions and the avoidance of artifacts allowed maximum validity. A special chamber was developed in which the samples were freely suspended and therefore were able to be scanned without generating mirror-image artifacts. Because of this special chamber and the ability to scan the samples with a linear velocity, the conditions were optimal for generating and analyzing the three-dimensional data sets.
The primary analysis was focused on the reproducibility of results. In this series normalized image analysis of carotid plaques achieved highly significant inter- and intra-observer reproducibility.

To allow comparison between the two- and three-dimensional data, each analyzed B-mode view was compared with several of the cuts from which the three-dimensional data set was generated. The GSM analysis of the single longitudinal view produced the same results as the multiple cross sectional analysis from the three-dimensional data set. We identified nearly complete concordance between the two methods. Repeat measurements with each of the two methods used in our study applied to the same subject resulted in a good agreement as well. Summarizing our findings, we postulate that the methods can be interchanged. Based on these findings, evaluation of GSM of internal carotid artery plaques with a three-dimensional method offers no advantages over the two-dimensional method that has been used thus far.

One limitation of the study is that we focused our evaluation on one aspect of carotid plaque imaging. Further aspects to demonstrate plaque morphology are plaque luminal morphology, and plaque volume. Therefore, the option of a 3D investigation could exceed the clinical value of a $2 \mathrm{D}$ measurement and might improve the visualization of carotid plaque morphology. Using intravascular ultrasound in addition to these other methods might be another way of improving ultrasound imaging of plaque morphology. Intravascular ultrasound of coronary arteries agreed well with histological findings $[23,24]$. The results of GSM analysis could also be improved using pixel distribution analysis and/or color mapping of particular regions of interest within the plaque. Evaluations utilizing these methods provided additional information about the histology of the plaque and had a strong correlation with the occurrence of neurological events and mortality $[13,25]$. Additional studies will be necessary to see if these detailed analyses are possible in vivo and under reduced resonance conditions, and whether they can also achieve successful acoustic shadowing of more calcified plaques.

\section{Conclusion}

$\checkmark$

The goal of this paper was to investigate in vitro whether $3 \mathrm{D}$ ultrasound is superior to $2 \mathrm{D}$ ultrasound for the evaluation of the GSM of atherosclerotic plaques in the extracranial internal carotid artery. For this purpose, a special chamber was designed to facilitate standardized scans while minimizing the number of artifacts. The results from GSM analysis based on 2D and 3D studies were comparable and highly reproducible. Therefore, in this regard there was no advantage to using the three-dimensional rather than two-dimensional method.

\section{References}

1 North American Symptomatic Carotid Endarterectomy Trial Collaborators. Beneficial effect of carotid endarterectomy in symptomatic patients with high-grade carotid stenosis. N Engl J Med 1991; 325: 445-453

2 Executive Committee for the Asymptomatic Carotid Atherosclerosis Study. Endarterectomy for asymptomatic carotid artery stenosis JAMA 1995; 273: 1421-1428

3 European Carotid Surgery Trialists's Collaborative Group. Randomised trial of endarterectomy for recently symptomatic carotid stenosis: final results of the MRC European Carotid Surgery Trial (ECST). Lancet 1998; 351: 1379-1387 
4 Denzel C, Balzer K, Muller KM et al. Imaging techniques for showing the morphology and surface structure of extracranial internal carotid artery plaques. Dtsch Med Wochenschr 2005; 130: 1267-1272

5 Iannuzzi A, Wilcosky T, Mercuri M et al. Ultrasonographic correlates of carotid atherosclerosis in transient ischemic attack and stroke. Stroke 1995; 26: 614-619

6 Matsagas MI, Vasdekis SN, Gugulakis AG et al. Computer-assisted ultrasonographic analysis of carotid plaques in relation to cerebrovascular symptoms, cerebral infarction, and histology. Ann Vasc Surg 2000; 14: $130-137$

7 Pedro LM, Pedro MM, Goncalves I et al. Computer-assisted carotid plaque analysis: characteristics of plaques associated with cerebrovascular symptoms and cerebral infarction. Eur J Vasc Endovasc Surg 2000; 19: $118-123$

8 Denzel C, Balzer K, Muller KM et al. Relative value of normalized sonographic in vitro analysis of arteriosclerotic plaques of internal carotid artery. Stroke 2003; 34: 1901-1906

9 Biasi GM, Sampaolo A, Mingazzini P et al. Computer analysis of ultrasonic plaque echolucency in identifying high risk carotid bifurcation lesions. Eur J Vasc Endovasc Surg 1999; 17: 476-479

10 Bland JM, Altman DG. Statistical methods for assessing agreement between two methods of clinical measurement. Lancet 1986: 307-310

11 Reiter M, Bucek RA, Effenberger I et al. Plaque echolucency is not associated with the risk of stroke in carotid stenting. Stroke 2006; 37: 2378-2380

12 Biasi GM, Froio A, Diethrich EB et al. Carotid plaque echolucency increases the risk of stroke in carotid stenting: the Imaging in Carotid Angioplasty and Risk of Stroke (ICAROS) study. Circulation 2004; 110: 756-762

13 Sztajzel R, Momjian-Mayor I, Comelli M et al. Correlation of cerebrovascular symptoms and microembolic signals with the stratified grayscale median analysis and color mapping of the carotid plaque. Stroke 2006; 37: 824-829

14 Kakkos SK, Stevens JM, Nicolaides AN et al. Texture Analysis of Ultrasonic Images of Symptomatic Carotid Plaques can Identify Those Pla- ques Associated with Ipsilateral Embolic Brain Infarction. Eur J Vasc Endovasc Surg 2007; 33: 422-429

15 Tegos TJ, Sohail M, Sabetai MM et al. Echomorphologic and histopathologic characteristics of unstable carotid plaques. AJNR Am J Neuroradiol 2000; 21: 1937-1944

16 Schminke U, Motsch L, Hilker L et al. Three-dimensional ultrasound observation of carotid artery plaque ulceration. Stroke 2000; 31: 16511655

17 Denzel C, Fellner F, Wutke $R$ et al. Ultrasonographic analysis of arteriosclerotic plaques in the internal carotid artery. Eur J Ultrasound 2003; 16: $161-167$

18 Stary $H C$, Chandler $A B$, Dinsmore RE et al. A Definition of Advanced Types of Atherosclerotic Lesions and a Histological Classification of Atherosclerosis: A Report From the Committee on Vascular Lesions of the Council on Arteriosclerosis, American Heart Association. Arterioscler Thromb Vasc Biol 1995; 15: 1512-1531

19 Jespersen SK, Wilhjelm JE, Sillesen $H$. Multi-angle compound imaging. Ultrason Imaging 1998; 20: 81-102

20 Landry A, Spence JD, Fenster A. Measurement of carotid plaque volume by 3-dimensional ultrasound. Stroke 2004; 35: 864-869

21 Ainsworth CD, Blake CC, Tamayo A et al. 3D ultrasound measurement of change in carotid plaque volume: a tool for rapid evaluation of new therapies. Stroke 2005; 36: 1904-1909

22 Wijeyaratne SM, Jarvis S, Stead LA et al. A new method for characterizing carotid plaque: multiple cross-sectional view echomorphology. J Vasc Surg 2003; 37: 778-784

23 Fujii K, Carlier SG, Mintz GS et al. Association of plaque characterization by intravascular ultrasound virtual histology and arterial remodeling. Am J Cardiol 2005; 96: 1476-1483

24 Uemura $R$, Tanabe J, Yokoyama $H$ et al. Impact of histological plaque characteristics on intravascular ultrasound parameters at culprit lesions in coronary artery disease. Int Heart J 2006; 47: 683-693

25 Lal BK, Hobson 2nd RW, Pappas PJ et al. Pixel distribution analysis of Bmode ultrasound scan images predicts histologic features of atherosclerotic carotid plaques. J Vasc Surg 2002; 35: 1210-1217 